\title{
Optimization of Aeration Time in the Development Theaflavin-3,3'-Digallate Rich Black Teas
}

\author{
Samuel Kimutai ${ }^{1}$, Thomas Kinyanjui ${ }^{1}$, John Wanyoko² ${ }^{2}$, Francis Wachira ${ }^{3}$, \\ Stephen Karori ${ }^{4}$, Augustine Muthiani ${ }^{4}$ \\ ${ }^{1}$ Department of Chemistry, Egerton University, Egerton, Kenya \\ ${ }^{2}$ KALRO-Tea Research Institute, Kericho, Kenya \\ ${ }^{3}$ Association for Strengthening Agricultural Research in East and Central Africa, Entebbe, Uganda \\ ${ }^{4}$ Department of Biochemistry, Egerton University, Egerton, Kenya \\ Email: samuelkimutai@gmail.com
}

Received 22 October 2015; accepted 4 December 2015; published 7 December 2015

Copyright (C) 2015 by authors and Scientific Research Publishing Inc.

This work is licensed under the Creative Commons Attribution International License (CC BY).

http://creativecommons.org/licenses/by/4.0/

c) (i) Open Access

\section{Abstract}

This study involved the selection of 11 cultivars out of 201 screened cultivars of fresh green and purple coloured tea leaves for use in the manufacture of black teas with optimized antioxidant activities. Individual cultivars containing a combination of high leaf concentrations of the catechin fractions; epicatechin gallate (ECG) and epigallocatechin gallate (EGCG) were used in the processing of theaflavin-3,3' digallate (TF3) rich black tea. The black tea enrichment with TF3 was carried out through optimization of the processing conditions of each cultivar by varying the aeration times between $0 \mathrm{~min}$ and $80 \mathrm{~min}$ at an interval of $20 \mathrm{~min}$. The differently processed teas were then assayed for the TF3 contents. The data analysis was carried out using the GENSTAT at $p \leq$ 0.05. The optimal processing time for Ejulu, TRFK 832/8, TRFK 831/11, TRFK 824/1, SC 31/37, SC $12 / 28$, K-Purple and TRFK $6 / 8$ was found to be $60 \mathrm{~min}$ while that of TRFK 301/6, TRFK 301/3 and TRFK 655/1 was $40 \mathrm{~min}$. The optimal TF3 levels were found to range from $0.19 \%$ to $0.60 \%$.

\section{Keywords}

Theaflavins, Catechins, Antioxidants

\section{Introduction}

Black tea is the second most consumed beverage in the world after water [1]. Since its introduction in Kenya

How to cite this paper: Kimutai, S., Kinyanjui, T., Wanyoko, J., Wachira, F., Karori, S. and Muthiani, A. (2015) Optimization of Aeration Time in the Development Theaflavin-3,3'-Digallate Rich Black Teas. American Journal of Plant Sciences, 6, 30013012. http://dx.doi.org/10.4236/ajps.2015.619295 
around 1904, tea cultivation has immensely expanded within the country to cover more than 157,000 hectares incorporating both small and large scale farming. Kenya is one of the major tea producing nations, and the world's largest exporter of black tea (accounting for $22 \%$ of the world exports), exporting over 400,000 tons of tea per year. Earnings from tea exports accounts for about $26 \%$ of the total foreign exchange and $4 \%$ of Kenya's GDP. For instance in 2013 alone, Kenya earned approximately \$1.09 billion from tea exports. Therefore the tea industry is an important component of economic development, supporting over three million people or $10 \%$ of the population either directly or indirectly [2]. However, the industry is currently experiencing a downturn due to dwindling returns to producers as a result of shrinking market outlets for the principle product produced in Kenya; black tea. For example, the annual average unit prices for processed black tea at the Mombasa auction fell by \$0.97, from an average high of US\$ 2.50 per Kg in the 1980s to a low of US\$ 1.95 in 2012 [3]. This is despite an increase in production costs by close to $317 \%$ over the same period.

Therefore, there is need for products diversification and value addition within the tea industry to include fast moving consumer goods and health products for the purposes of increasing the market outlets with commensurate increase in profitability and sustainability [4]. Notably, owing to the history of the East African tea market, Kenyan tea is rarely sold as a finished branded product and ends up being blended with teas of lesser quality grown elsewhere in the world before being sold as a generic product. There needs to be a change in the way Kenya's tea industries processes and markets black tea so as the farmers are to get a fair return from their farming enterprises.

There are three common varieties of tea products that are widely consumed: black, green and oolong tea. The processing method of the harvested leaves determine the nature of the tea product [5]. The manufacturing process in black involves weathering the leaves to reduce moisture content, and then macerating them to initiate oxidation by an enzyme known as polyphenol oxidase. This reaction enables the polymerization of catechins (one of the major polyphenolic compounds in tea) to form theaflavins (TFs) and thearubigins (TRs), a group of homogenous substances, responsible for the yellowish brown coloration in black tea beverage [6] [7]. In green tea processing on the hand, the withered leaves are steamed to inactivate polyphenol oxidase thus minimizing the chemical and enzymatic reactions leaving the catechins intact. The oolong tea is processed by partial aeration of the fresh green leaves before drying [8]. The other varieties of teas are categorized as the "specialty teas" like the purple, white and yellow tea. Purple tea is a term referred to both the black and green teas processed from purple tea leaves. There is no general accepted definition of white tea and very little international agreement [4].

Black tea TFs comprise the bulk of polyphenolic compounds found in the beverage. Theaflavins are dimers of epimerized catechins, and are usually formed during black tea tea aeration [9]. Theaflavins are composed of various fractions namely; $T F 1, \mathrm{TF}_{2} \mathrm{~A}, \mathrm{TF}_{2} \mathrm{~B}$ and $\mathrm{TF} 3$ [10]. TFs are antioxidants in nature and each of the fractions is different from the other in how they scavenge the reactive oxygen species (ROS) both in vivo and in vitro [11]. The hierarchy of reactivity of these compounds as antioxidants is: TF3 > TF2A = TF2B > TF1 [12]. The amount of the individual theaflavins formed are largely influenced by the amount of the precursor catechins in green leaf, the redox potential and/or affinity for polyphenol oxidase and activity [12]. Black teas contain varying amounts of the four individual theaflavins and each of them have different astringency and therefore contribute variably to the overall quality of plain black tea. Theaflavin-3,3'-digallate is 6.4 times while the theaflavin monogallates are 2.22 times more astringent than theaflavin. Although determination of total theaflavin has been used in the determination of black tea quality, individual theaflavins especially theaflavin digallate is also important because it can better describe the quality of black teas [13].

Free radicals in excess are harmful since they cannot be quenched by the body antioxidant enzymes, such as the peroxidases and catalases. Free radicals damage cell membranes by causing harmful chain reactions such as DNA base oxidation, and lipid peroxidation [14]. They have also been implicated to play a role in aging and various diseases, such as cancer, cataract and atherosclerosis. Antioxidant supplements, such as vitamin $\mathrm{C}$ and vitamin E and from plant oils and fruits have been used as therapeutic agents [15]-[18] for averting the risk of these diseases.

Various studies have been done on the ability of TFs to inhibit superoxide, hydroxyl radical, hydrogen peroxide, singlet oxygen and their effects on free radical induced DNA oxidative damage [15]-[21]. The TF3 has been found be most potent of the four fractions in scavenging hydrogen peroxide and hydroxyl radical, while $\mathrm{TF}_{1}$ is a potent suppressor of superoxide. The $\mathrm{TF} 2_{\mathrm{A}} \mathrm{TF}_{2} \mathrm{~B}$ have similar antioxidant capacities and are relatively good scavengers of singlet oxygen, hydroxyl radical, hydrogen peroxide and the hydroxyl radical-induced DNA damage 
[21]. However their antioxidant capacities are lower compared to TF3. The TF3 is also thought to possess a higher antioxidative capacity than catechins, including EGCG [22]. Research studies have also shown TF3 to have anti-inflammatory properties [16] [23] and the mechanism involves blocking the conversion of arachidonate to prostaglandins by inhibiting the production of the enzymes cyclooxigenase (COX) and lipoxygenase (LOX) [16] [23] [24].

The optimization of processing conditions development that can lead to the production of black teas with enhanced TF3 and antioxidative would increase the nutritional value of the beverage and hence market the product as a health enhancing drink. It is anticipated that this study will enhance the intrinsic value of tea for both local and export markets resulting in improved incomes to the Kenyan tea industry stakeholders.

\section{Materials and Method}

\subsection{Sample Selection and Sampling}

Eleven different tea cultivars (green and purple leaf) endowed with high levels of EGCG and ECG in a ratio of 1:1 were selected for use as raw materials in the processing of TF3 rich black teas. The ranking of the cultivars was carried out according to the order of their ratio of ECG to EGCG. The cultivars included; Ejulu, TRFK 301/6, TRFK 832/8, TRFK 655/1, TRFK 301/3, TRFK 831/11, TRFK 824/1, SC 31/37, SC 12/28, K-Purple and TRFK 6/8. The selection of these cultivars was guided by results got from previous screening of 201 cultivars. The sampling was done in duplicates. About $500 \mathrm{~g}$ of fresh two leaves and a bud was plucked from selected tea cultivars and placed in labeled khaki bags to prevent moisture loss. They were then transferred into a cool box containing ice packs (to preserve catechins) and delivered to the miniature factory for processing.

\subsection{Black Tea Enrichment with TF3}

The enrichment process of the individual black tea of the selected cultivars with high levels of TF3 involved optimization of the aeration times during the manufacturing process of the teas. The optimization of the aeration process was done by varying the aeration times from 0 to 80 minutes at an interval of 20 minutes, $(0,20,40,60$ and 80 minutes), hence each cultivar produced five samples amounting to a total of fifty five samples for the eleven cultivars. Usually the processing time for all the black teas in Kenyan tea processing is 90 min. However, a maximum of 80 minutes was chosen for this study since various tea researchers [13] [25]-[28] had found out that at 90 min aeration time all most of TF fractions regardless of the cultivar had began to deteriorate. The black tea samples processed at each of the aeration times were characterized for their TF3 levels to ascertain the aeration time at which their contents were maximal.

\subsection{Black Tea Optimization of the Processing Conditions.}

About $500 \mathrm{~g}$ of the plucked leaves were weighed and withered at room temperature $\left(25^{\circ} \mathrm{C}\right)$ for 19 hours. The leaves were then macerated using the curl tear and cut (CTC) machine. The macerated leaves from each of the selected cultivar were then divided into five samples and fermented at $24^{\circ} \mathrm{C}$ at time intervals of $0 \mathrm{~min}, 20 \mathrm{~min}$, $40 \mathrm{~min}, 60 \mathrm{~min}$ and 80 minutes respectively. After that, the fermented leaves were dried at $130^{\circ} \mathrm{C}$ to a moisture content of 3\% - 5\% [4]. Finally, the processed leaves were ground to a fine powder and packaged for analysis.

\subsection{Quantification of TF3 and Other TF Fractions}

The determination of the TF3 concentration together with those of the other TF fractions on the differently processed black teas was carried out using Reverse Phase High Performance liquid Chromatography (RPHPLC). The model of the HPLC machine used was Shimadzu LC 20 make fitted with a SIL 20A auto sampler and a SPD-20 UV-Visible detector (set at $210 \mathrm{~nm}$ ) with a class LC10 chromatograph workstation, and a C18 ODS column manufactured in Kyoto, Japan [2]. Four grams black tea was weighed into a $475 \mathrm{ml}$ thermos flask, and an infusion made by adding $200 \mathrm{ml}$ of boiling double distilled water. The thermos's lid was closed tightly and placed in a mechanical shaker for ten minutes after which the sample was filtered through a cotton wool into a $500 \mathrm{ml}$ conical flask. Two milliliters of each sample was pipetted into $10 \mathrm{ml}$ plastic test tubes and diluted with of $2 \mathrm{ml}$ of double distilled water. The samples were then vortexed and placed in a centrifuge machine set at 60 rpm for 15 minutes. After that $20 \mu \mathrm{L}$ of each of the samples was injected onto HPLC. The wavelength was set at 
$378 \mathrm{~nm}$ and flow rate at $1.5 \mathrm{ml} / \mathrm{min}$. The mobile phases used consisted of two solvents; Solvent A which comprised of $1 \%$ acetic acid solvent B was acetonitrile. A linear gradient starting from $8 \%$ to $31 \%$ of the second solvent B over 1 hour was used [29]. The TF3 and the other individual TF fractions levels were then calculated from the peak areas of chromatograph and expressed as a percentage of the total dry black tea weight.

\subsection{Data Analyses}

All statistical analyses were carried out using the GENSTAT Discovery Edition 4 packages. Data was presented as Tables and graphs. The ANOVA table and DMRT was be used to compare the quality of the developed teas with those in the market (reference standard). Probability limits was set as $p \leq 0.05$.

\section{Results and Discussion}

\subsection{Optimization of the TF3 Levels for Black Teas of the Eleven Selected Cultivars}

The results on the optimization of the aeration times for each of eleven selected cultivars are as shown in Figures 1-11. Ejulu is a commercial cultivar and was used as a reference standard since it has been found to have the highest TF3 levels and therefore used in the TRI as one of quality standard cultivars. Cultivar TRFK 6/8 is another commercial cultivar that was used since it has been known to have the highest levels of both simple TF and total TFs and used as a quality standard.

\subsubsection{Ejulu}

Figure 1 shows the levels of TF3 for the black teas processed at each of the aeration times. There was a significant $p<0.05$ difference in the levels of TF3 contents for this cultivar when processed between 0 min and 80 min aeration time where the highest TF3 levels were reached at $60 \mathrm{~min}$ aeration time $(0.45 \%)$, while the lowest levels were found at $0 \mathrm{~min}$ aeration time $(0.13 \%)$. However there was no significant $p<0.05$ difference in the TF3

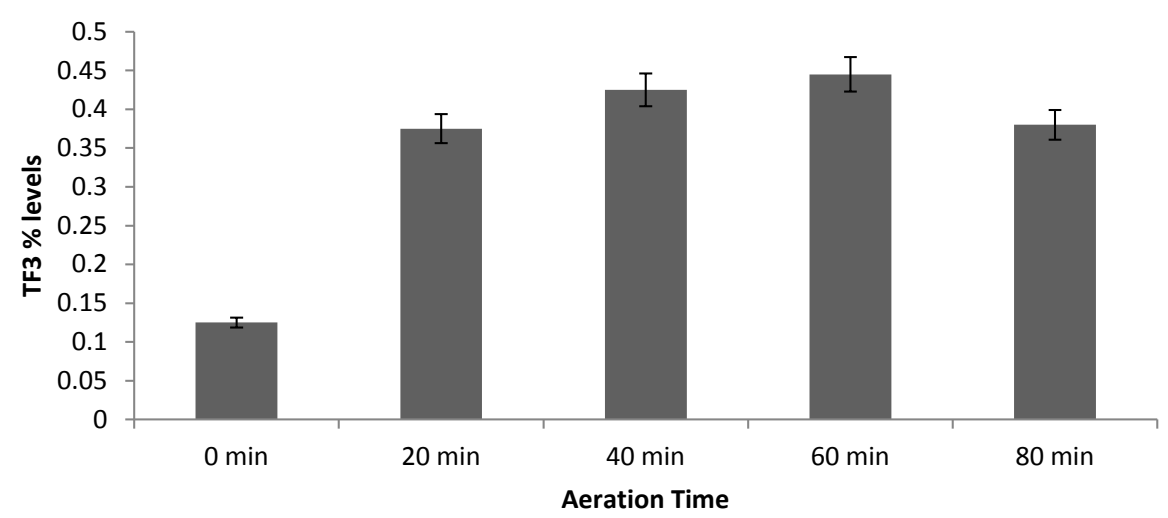

Figure 1. Optimization of the aeration time for Ejulu in the processing of TF3 rich black tea.

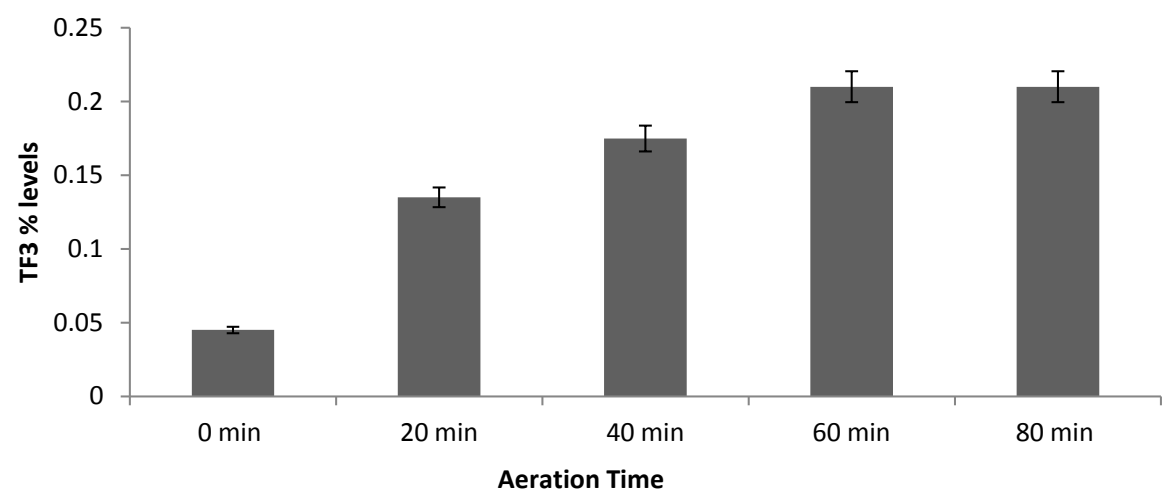

Figure 2. Optimization of the aeration time for TRFK 6/8 in the processing of TF3 rich black tea. 


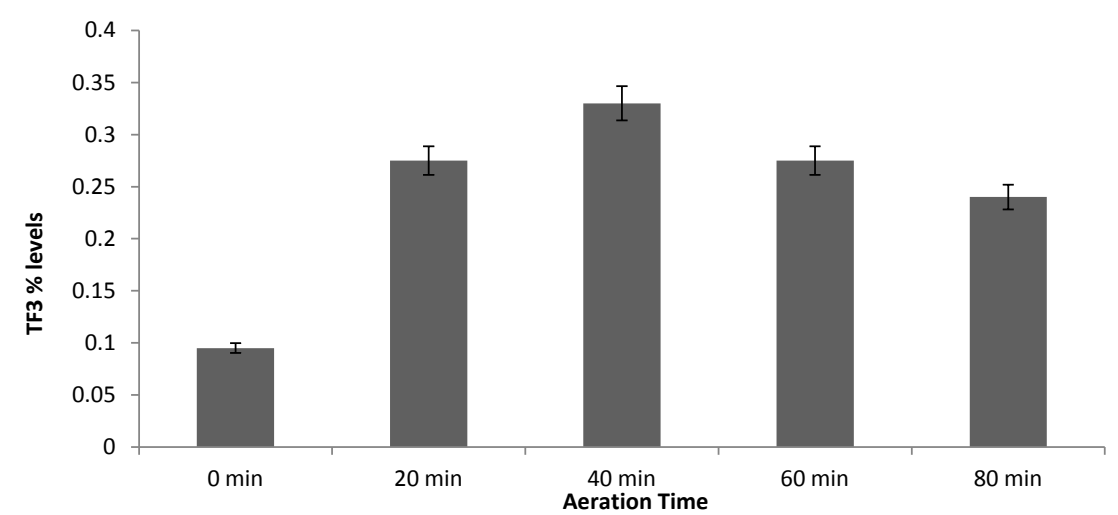

Figure 3. Optimization of the aeration time for TRFK 301/6 in the processing of TF3 rich black tea.

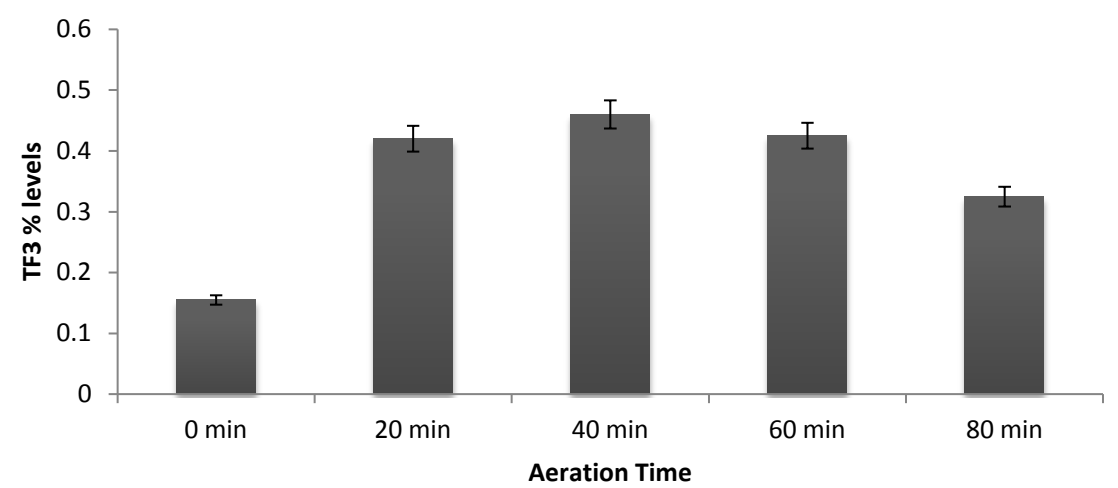

Figure 4. Optimization of the aeration time for TRFK 655/1 in the processing of TF3 rich black tea.

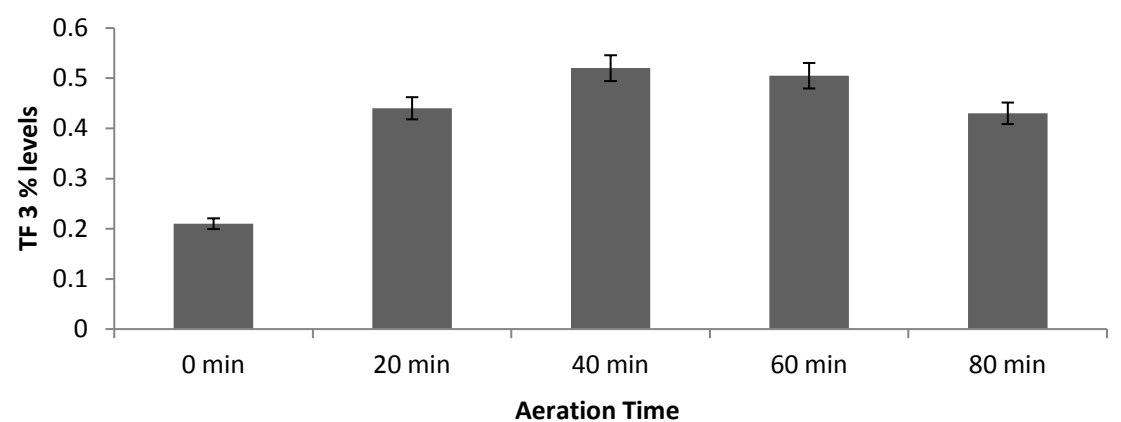

Figure 5. Optimization of the aeration time for TRFK 301/3 in the processing of TF3 rich black tea.

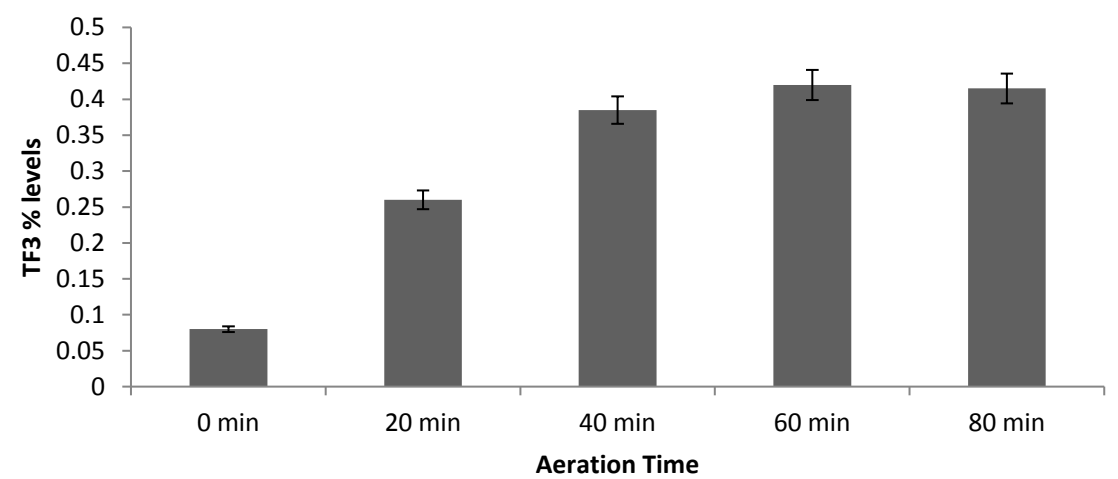

Figure 6. Optimization of the aeration time for SC 31/37 in the processing of TF3 rich black tea. 


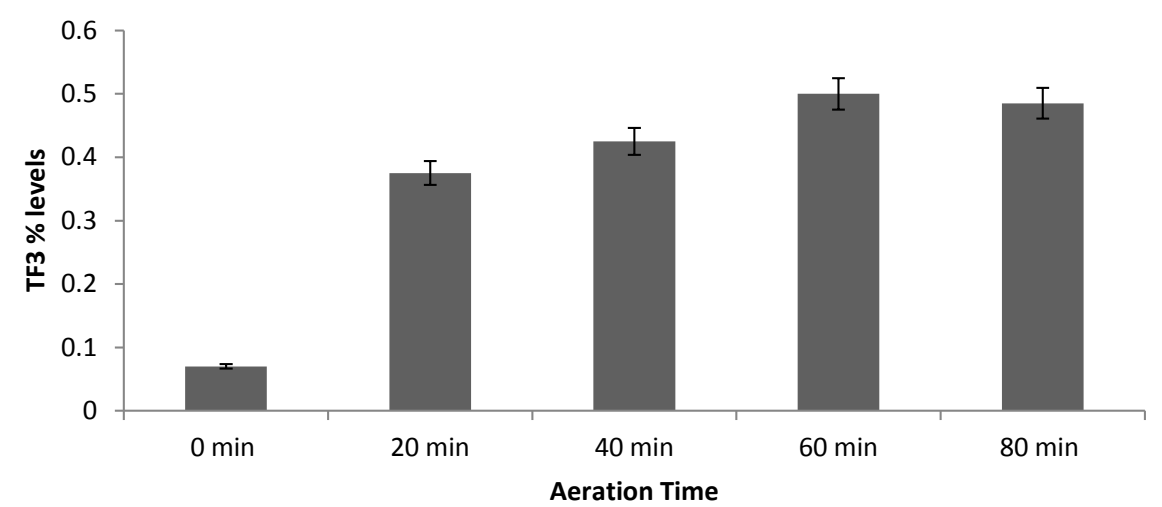

Figure 7. Optimization of the aeration time for SC 12/28 in the processing of TF3 rich black tea.

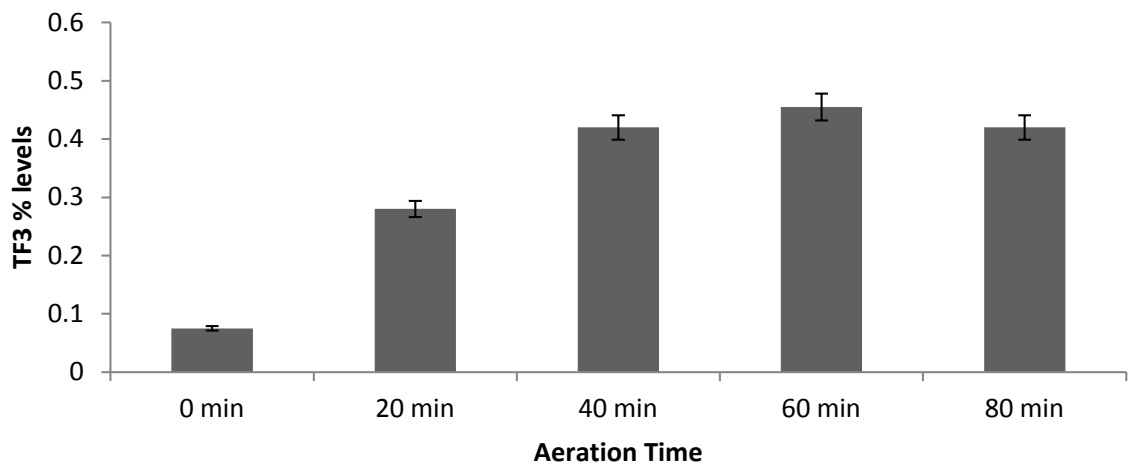

Figure 8. Optimization of the aeration time for TRFK 831/11 in the processing of TF3 rich black tea.

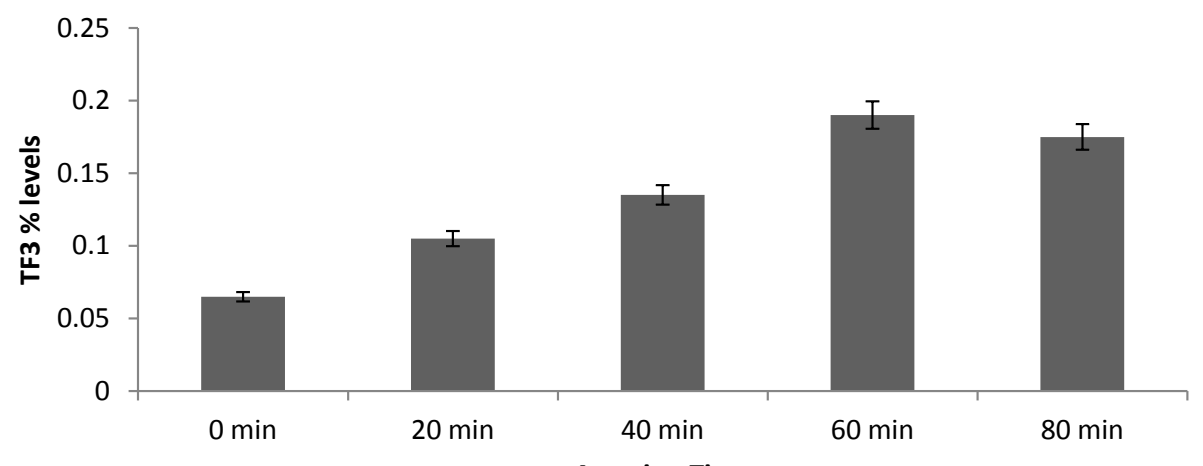

Figure 9. Optimization of the aeration time for K-purple in the processing of TF3 rich black tea.

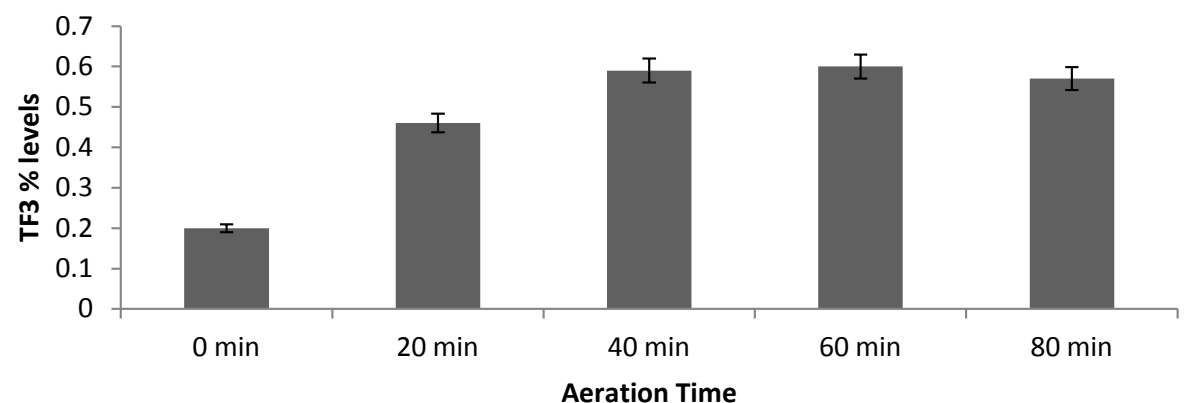

Figure 10. Optimization of the aeration time for TRFK 832/8 in the processing of TF3 rich black tea. 


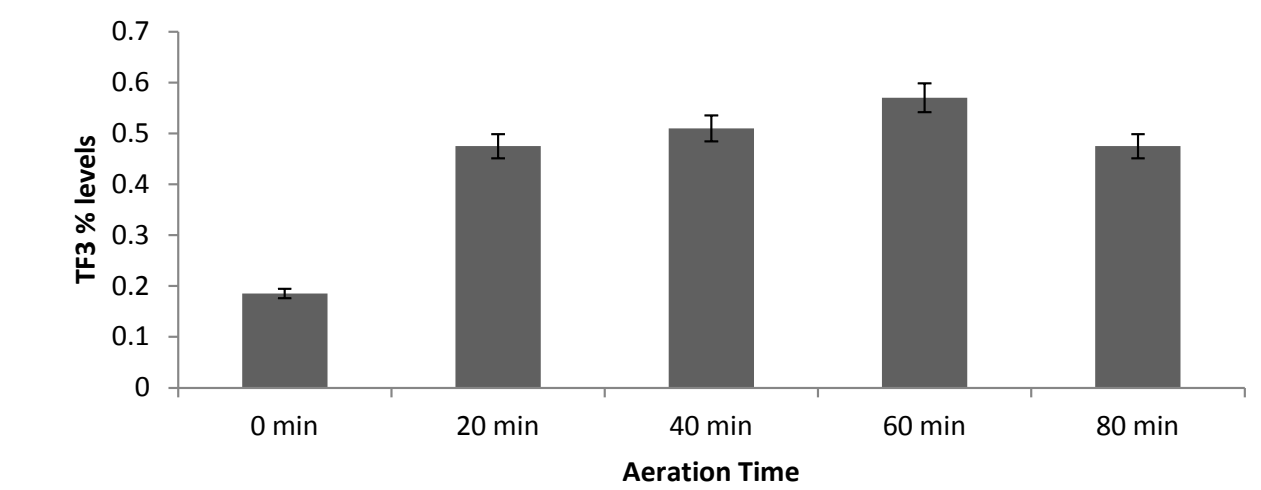

Figure 11. Optimization of the aeration time for TRFK 824/1 in the processing of TF3 rich black tea.

levels for this cultivar when processed at $40 \mathrm{~min}$ and $60 \mathrm{~min}$ aeration time. At 0 min aeration time, there is limited interaction between oxygen and the macerated leaves necessary for TF3 formation, hence their low levels. Increased exposure time of the ground leaves to oxygen, leads to more conversion of EGCG and ECG to TF3. At 80 min aeration time, the TF3 levels declined significantly. The TF3 levels for Ejulu is known to be $(0.41 \%)$, [2] when the cultivar is processed using the standard aeration time of $90 \mathrm{~min}$. This confirms further deterioration of the TF3 with extended aeration time beyond $80 \mathrm{~min}$. Therefore, to obtain TF3 rich black tea from the cultivar, it should be processed at 60 min aeration time.

The fresh leaves of this cultivar however had the highest combination of ECG and EGCG among all the other selected cultivars, (5.69\% and $6.16 \%$ respectively). This explains the reason for its relatively high levels of TF3. This values are different from the ones reported by [2] of 3.26\% and $4.66 \%$ respectively. The fluctuations in the ECG and EGCG levels in the fresh leaves could be attributed to both seasonal and geographical variations [30].

\subsubsection{TRFK $6 / 8$}

Figure 2 shows the TF3 levels of the cultivar's black teas processed at different aeration times, where there was a significant $p<0.05$ difference in TF3 contents. Processing the cultivar at $60 \mathrm{~min}$ and $80 \mathrm{~min}$ aeration time produced black tea with the highest TF3 levels $(0.21 \%)$ while processing at 0 min aeration time gave black teas with the lowest TF3 levels (0.045\%). The TF3 levels significantly increased with increased aeration time from 0 min to 60 min and then remained constant at 80 min aeration time meaning that optimal aeration time for the cultivar could be between $60 \mathrm{~min}$ and 80 min aeration time. The TF3 levels of the cultivar's black tea had been reported [2] to be $(0.29 \%)$ when processed at 90 min aeration time. The fermentability test results revealed the cultivar as a slow fermenter [31] which could be the reason for the increased levels of TF3 levels at 90 min aeration time. However, due to the cultivar's relatively low TF3 levels, it may not be suitable for the manufacture of TF3 rich black tea. The ECG and EGCG profiles for the cultivars fresh leaves where found to be $2.47 \%$ and $6.84 \%$ from the previous screening studies. The lack of correct balance between the ECG and EGCG could be the reason for the low TF3 contents reported for the cultivar's black tea [32]. TFFK 6/8 is one of the oldest cultivars in the TRFK and has been used in the genetic breeding program for the development of superior quality germplasms. The optimum aeration time used to process black tea of the cultivar had been found to be 90 min based on the total TF levels [33]. The 90 min aeration time was set as the standard processing time by most Kenyan tea factories as the for all the black teas regardless of the cultivar type.

\subsubsection{TRFK 301/6, TRFK 655/1 and TRFK 301/3}

Figure 3 is a representation of the TF3 levels of the differently processed black teas of TRFK 301/6. There were notable $p<0.05$ differences in the TF3 levels for the black teas where the highest TF3 levels was formed at 40 min aeration time $(0.33 \%)$ and lowest levels at 0 min aeration time $0.095 \%$. The TF3 levels increased significantly with increased aeration time from $0 \mathrm{~min}$ to $40 \mathrm{~min}$. At $60 \mathrm{~min}$ aeration time, the TF3 levels began to deteriorate significantly. There was no significant $p>0.05$ difference in TF3 levels for the black teas processed at 20 min and 60 min aeration time for this cultivar.

Figure 4 shows TF3 levels for black teas of TRFK 655/1 processed at different aeration times. The cultivar had its optimal TF3 levels at 40 min aeration time (0.46\%). Lowest TF3 levels where exhibited at 0 min aeration time (0.16\%). There was no significant $p<0.05$ difference in TF3 levels when the cultivar was processed at 20 
min and 60 min aeration time just like TRFK 301/3. At 60 min aeration time, the TF3 levels declined.

Figure 5 is a representation of TF3 for the cultivar TRFK 301/3 processed at different aeration times. The cultivar attained its optimal TF3 levels at 40 min aeration time $(0.52 \%)$ while the lowest TF3 levels were exhibited at 0 min aeration time. Even though there was no significant $p<0.05$ difference in the TF3 levels when the cultivar was processed at $40 \mathrm{~min}$ and $60 \mathrm{~min}$ aeration time, it can be seen that the TF3 levels began to decline when the cultivar was processed at 60 min aeration time. Out of the three cultivars, TRFK 301/3 had the highest TF3 levels at the optimum aeration time followed by TRFK 655/1 and TRFK 301/6. The three cultivars are test clones and have not yet been released by TRFK for commercial production. TRFK 301/3 had notably higher levels of TF3 than those of reference standard Ejulu while TRFK 655/1 had comparable TF3 amounts with Ejulu. TRFK 301/6 had a siginificantly lower TF3 levels than Ejulu.

From results, it can be concluded that in order to process TF3 rich black teas from TRFK 301/6, TRFK 655/1 and TRFK 301/3, the cultivars should be processed at $40 \mathrm{~min}$ aeration time. The optimal aeration time for the three cultivars were lower than those of the reference standards $(60 \mathrm{~min})$. This shows that the optimal aeration times used in black tea processing is unique for each cultivar and that subjecting all cultivars to the same processing conditions might compromise the black tea quality, a conclusion that is in tandem with [34] findings.

From the previous screening studies of fresh green leaves, TRFK 301/3 had the highest EGCG to ECG ratio of 1.51, while that of TRFK 655/1 was 0.96 and that of TRFK 301/6 was 0.70 . The high TF3 levels reported for the black tea of TRFK 301/3 could be attributed to the high EGCG to ECG ratio of the cultivar's fresh leaves while the relatively low TF3 levels in TRFK 301/6 could be due to the low EGCG to ECG ratio of the cultivar's green leaves. This observation is consistent with what [32] found out. In their studies, the authors reported that a correct balance of the catechin ratios was a necessary factor in the processing of black teas with optimized TF levels.

\subsubsection{SC $31 / 37$ and SC $12 / 28$}

Figure 6 shows the TF3 levels of black teas manufactured from SC 31/37 at different processing conditions. There were significant $p<0.05$ differences in TF3 levels when the cultivar was processed between 0 min and 80 min aeration time with highest TF3 levels being reached at $60 \mathrm{~min}$ aeration time $(0.52 \%)$ and the lowest levels at 0 min aeration time $(0.08 \%)$. There was no significant difference in the TF3 contents when the cultivar was processed at $60 \mathrm{~min}$ and $80 \mathrm{~min}$ aeration time. However, there was a slight deterioration in TF3 contents observed at 80 min aeration time.

Figure 7 represents the results of TF3 levels of black tea samples manufactured from SC 12/28 processed at different aeration times. A significant $p<0.05$ difference was observed in TF3 levels with respect to aeration time where the highest levels were exhibited at $60 \mathrm{~min}$ aeration time $(0.50 \%)$ while the least levels were found in 0 min aeration time (0.07\%). The was no notable difference in TF3 levels when this cultivar was processed between $60 \mathrm{~min}$ and $80 \mathrm{~min}$ aeration time, although there was a slight decline in the levels at $80 \mathrm{~min}$ aeration time.

Both SC 31/37 and SC 12/28 exhibited higher TF3 levels at 60 min aeration time than the reference standard Ejulu despite all of them sharing the same optimal aeration times. SC 31/37 had the highest EGCG to ECG ratio of 2.00 which explains the reason for the cultivar's relatively high TF3 levels. Both SC 31/37 and SC 12/28 have not yet been released by TRI for commercial production however, they show promising prospects with regards to antioxidative compounds and yield per hector [31].

\subsubsection{TRFK $831 / 11$}

Figure 8 shows the results of the TF3 levels of the cultivar's black teas processed at different aeration times. Significant $p<0.05$ differences in TF3 levels between the differently processed black teas were reported with the highest TF3 contend being reached at $60 \mathrm{~min}$ aeration time $(0.46 \%)$ and the lowest levels at 0 min aeration time $(0.075 \%)$. The TF3 levels increased with increasing aeration time, however beyond 60 min aeration time the TF3 levels declined. It is therefore recommended that TF3 rich black tea for this cultivar should be processed at 60 min aeration time. The optimal TF3 levels for this cultivar is comparable to that of the reference standard Ejulu (0.45\%).

\subsubsection{K-Purple}

The results for the TF3 levels of the differently processed black teas of the cultivar are represented in Figure 9. 
There were significant $p<0.05$ differences in the variations of the levels of TF3 of the differently processed teas where the optimal TF3 contents were reached at $60 \mathrm{~min}$ aeration time $(0.19 \%)$ and lowest levels at 0 min aeration time $(0.065 \%)$. The optimal TF3 levels for the cultivar are the lowest reported so far. It is important to note that the selection criteria for this cultivar was not based on the EGCG to ECG ratio since purple coloured cultivars have always been reported to have low catechin levels, but rather on the fact that tea researchers at TRFK [4] had found the cultivar to produce good quality black teas. Its good black tea quality attributes could be due to anthocynanins, which are known to have sweet smelling aroma [2]. Whereas the cultivar might be suitable for the processing of anthocyanin rich tea, it might not be in fact suitable for the processing of TF3 rich black tea.

\subsubsection{TRFK $832 / 8$ and TRFK $824 / 1$}

TRFK 832/8 cultivar had the highest TF3 levels at 60 min aeration time $(0.6 \%)$ and the lowest levels at 0 min aeration time (0.2\%) as shown in Figure 10. There was no significant $p<0.05$ difference in the TF3 levels when processing the cultivar between $40 \mathrm{~min}$ and $60 \mathrm{~min}$. Beyond $60 \mathrm{~min}$ aeration time, the TF3 levels began to decline.

Figure 11 is the representation of variation in TF3 levels of the differently processed black teas of TRFK 824/1. As can be seen from the graphs, there were significant $p<0.05$ variations in TF3 levels with the highest TF3 concentration being reached at 60 min aeration time $(0.57 \%)$ and lowest levels at 0 min aeration time (0.19\%). Beyond 60 min aeration time, the TF3 levels deteriorated.

For most clones, there was an increase in the TF3 levels with the aeration time from 0 to $60 \mathrm{~min}$. Beyond 60 min aeration time, the TF3 levels began to decline. This trend corroborates the findings got from studies done by [9] [35]. The decrease in individual theaflavins with increased aeration time beyond 60 min could be because of their conversion to thearubigins [33]. Studies on the effects of processing parameters on black tea chemical and sensory quality have revealed a decline in the levels of total theaflavins, liquor brightness, and briskness, with extended aeration time and rise in temperature [13]. When processing black tea, aeration time is important, since both increase and decrease in aeration time can lead to poor quality tea [36]. For the processing of TF3 rich black tea, it is critical to determine and use correct aeration time.

Both TRFK 832/8 and TRFK 824/1 exhibited the highest levels of TF3 among all the other cultivars. From the previous screening studies, TRFK 832/8 had an EGCG to ECG ratio of 1.08 while TRFK 824/1 EGCG to ECG ratio was 1.40. Out of all the cultivars TRFK 831/11 had the highest EGCG to ECG ratio of 2.0. One would expect that the order of ranking of the cultivars based on the EGCG to ECG ratios during the selection process would reflect a similar pattern on manufactured black teas [37]. However, this seems not always to be the case. Although the precursor compounds in the cultivars largely determine the amount of TF3 levels formed in the manufactured teas, there could be other genetic factors that influence the amounts of TF3 formed [7] [38] [39].

Eight out of the eleven cultivars (Ejulu, TRFK 832/8, TRFK 831/11, TRFK 824/1, SC 31/37, SC 12/28, K-Purple and TRFK 6/8) attained their optimal TF3 contents at 60 min aeration time while only three (TRFK 301/6, TRFK 301/3 and TRFK 655/1) cultivars had their maximum TF3 concentrations at 40 mins aeration time. This shows that not all TF3 molecules are formed at the same rate and to same extent under the same black tea processing conditions. Thus the levels of TF3 and their rate of formation is unique to a cultivar and a change in aeration time for optimal quality parameter achievement in one cultivar cannot be extrapolated to another cultivar [13]. The differences in the optimal aeration times between the clones could be as a result of variations in genetic makeup between the cultivars [40].

Although optimal aeration time is largely dependent on cultivar type, geographical factors could also influence processing time at which the antioxidant molecules are at their optimal levels. Iranian cultivars have been found to reach the peak faster than the Kenyan cultivars [41] [42].

\section{Conclusion}

From this study, the data obtained demonstrate that the TF3 concentrations in each cultivar vary significantly with the treatment. For cultivars Ejulu, TRFK 832/8, TRFK 831/11, TRFK 824/1, SC 31/37, SC 12/28, K-Purple and TRFK 6/8, the optimal aeration time was found to be 60 min while that of TRFK 301/6, TRFK 301/3 and TRFK 655/1 was 40 min. Processing black teas beyond 60 mins resulted in the deterioration of the TF3 levels in most of the cultivars. 


\section{Acknowledgements}

The author's would like to thank the Tea Research Institute, for allowing them to publish this work and National Council of Science and Technology Innovation for funding this project.

\section{References}

[1] Cabrera, C., Giménez, R. and López, M.C. (2003) Determination of Tea Components with Antioxidant Activity. Journal of Agricultural and Food Chemistry, 51, 4427-4435. http://dx.doi.org/10.1021/jf0300801

[2] Kilel, E.C., Wanyoko, J.K., Faraj, A.K. and Wachira, F.N. (2013) Plain Black Tea Quality Parameters of Purple Leaf Coloured Tea Clones in Kenya. International Journal of Research in Chemistry and Environment, 3, 81-88.

[3] Wamalwa, B.P. (2014) Sustainable Supply Chain Management as a Strategic Tool for Competitive Advantage in Tea Industry in Kenya. Journal of Management and Sustainability, 4, 157-164. http://dx.doi.org/10.5539/jms.v4n3p157

[4] Kerio, L.C., Wachira, F.N., Wanyoko, J.K. and Rotich, M.K. (2012) Characterization of Anthocyanins in Kenyan Teas: Extraction and Identification. Food Chemistry, 131, 31-38. http://dx.doi.org/10.1016/j.foodchem.2011.08.005

[5] Khokhar, S. and Magnusdottir, S.G.M. (2002) Total Phenol, Catechin, and Caffeine Contents of Teas Commonly Consumed in the United Kingdom. Journal of Agricultural and Food Chemistry, 50, 565-570. http://dx.doi.org/10.1021/jf010153l

[6] Way, T.-D., Lee, H.-H., Kao, M.-C. and Lin, J.-K. (2004) Black Tea Polyphenol Theaflavins Inhibit Aromatase Activity and Attenuate Tamoxifen Resistance in HER2/Neu-Transfected Human Breast Cancer Cells through Tyrosine Kinase Suppression. European Journal of Cancer, 40, 2165-2174. http://dx.doi.org/10.1016/j.ejca.2004.06.018

[7] Lin, Y.L., Tsai, S.H., Lin-Shiau, S.Y., Ho, C.T. and Lin, J.-K. (1999) Theaflavin-3,3’-Digallate from Black Tea Blocks the Nitric Oxide Synthase by Down-Regulating the Activation of NF- $\kappa$ B in Macrophages. European Journal of Pharmacology, 367, 379-388. http://dx.doi.org/10.1016/S0014-2999(98)00953-4

[8] Harbowy, M.E. and Balentine, D.A.D.A. (1997) Tea Chemistry. Critical Reviews in Plant Sciences, 16, 415-480. http://dx.doi.org/10.1080/07352689709701956

[9] Tüfekci, M. and Güner, S. (1997) The Determination of Optimum Aeration Time in Turkish Black Tea Manufacture. Food Chemistry, 60, 53-56. http://dx.doi.org/10.1016/S0308-8146(96)00302-0

[10] Yoshino, K., Yamazaki, K. and Sano, M. (2010) Preventive Effects of Black Tea Theaflavins against Mouse Type IV Allergy. Journal of the Science of Food and Agriculture, 90, 1983-1987. http://dx.doi.org/10.1002/jsfa.4035

[11] Wu, Y., Li, W., Xu, Y., Jin, E. and Tu, Y. (2011) Evaluation of the Antioxidant Effects of Four Main Theaflavin Derivatives through Chemiluminescence and DNA Damage Analyses. Journal of Zheijang University Science B, 12, 744751. http://dx.doi.org/10.1631/jzus.B1100041

[12] Owuor, P. (1995) Clonal Variation in the Individual Theaflavin Levels and Their Impact on Astringency and Sensory Evaluations. Food Chemistry, 54, 273-277. http://dx.doi.org/10.1016/0308-8146(95)00046-L

[13] Owuor, P.O. and Obanda, M. (2001) Comparative Responses in Plain Black Tea Quality Parameters of Different Tea Clones to Aeration Temperature and Duration. Food Chemistry, 72, 319-327. http://dx.doi.org/10.1016/S0308-8146(00)00232-6

[14] Yang, Z., Tu, Y., Xia, H., Jie, G., Chen, X. and He, P. (2007) Suppression of Free-Radicals and Protection against $\mathrm{H}_{2} \mathrm{O}_{2}$-Induced Oxidative Damage in HPF-1 Cell by Oxidized Phenolic Compounds Present in Black Tea. Food Chemistry, 105, 1349-1356. http://dx.doi.org/10.1016/j.foodchem.2007.05.006

[15] Anandhan, A., Tamilselvam, K., Radhiga, T., Rao, S., Essa, M.M. and Manivasagam, T. (2012) Theaflavin, a Black Tea Polyphenol, Protects Nigral Dopaminergic Neurons against Chronic MPTP/Probenecid Induced Parkinson's Disease. Brain Research, 1433, 104-113. http://dx.doi.org/10.1016/j.brainres.2011.11.021

[16] Aneja, R., Odoms, K., Denenberg, A.G. and Wong, H.R. (2004) Theaflavin, a Black Tea Extract, Is a Novel AntiInflammatory Compound. Critical Care Medicine, 32, 2097-2103. http://dx.doi.org/10.1097/01.CCM.0000142661.73633.15

[17] Antioxidants, E., Leung, L.K., Su, Y., Chen, R., Zhang, Z., Huang, Y. and Chen, Z. (2001) Theaflavins in Black Tea and Catechins in Green Tea Are Equally. Society, 1, 2248-2251.

[18] Babich, H., Gottesman, R.T., Liebling, E.J. and Schuck, A.G. (2008) Theaflavin-3-Gallate and Theaflavin-3'-Gallate, Polyphenols in Black Tea with Prooxidant Properties. Basic \& Clinical Pharmacology \& Toxicology, 103, 66-74. http://dx.doi.org/10.1111/j.1742-7843.2008.00232.x

[19] Betts, J.W., Wareham, D.W., Haswell, S.J. and Kelly, S.M. (2013) Antifungal Synergy of Theaflavin and Epicatechin Combinations against Candida albicans. Journal of Microbiology and Biotechnology, 23, 1322-1326. http://dx.doi.org/10.4014/jmb.1303.03010 
[20] Chow, H.H.S. and Hakim, I.A. (2011) Pharmacokinetic and Chemoprevention Studies on Tea in Humans. Pharmacological Research, 64, 105-112. http://dx.doi.org/10.1016/j.phrs.2011.05.007

[21] Feng, Q., Torii, Y., Uchida, K., Nakamura, Y., Hara, Y. and Osawa, T. (2002) Black Tea Polyphenols, Theaflavins, Prevent Cellular DNA Damage by Inhibiting Oxidative Stress and Suppressing Cytochrome P450 1A1 in Cell Cultures. Journal of Agricultural and Food Chemistry, 50, 213-220. http://dx.doi.org/10.1021/jf010875c

[22] Karori, S.M., Wachira, F.N., Wanyoko, J.K. and Ngure, R.M. (2007) Antioxidant Capacity of Different Types of Tea Products. African Journal of Biotechnology, 6, 2287-2296.

[23] Krishnan, R. and Maru, G.B. (2004) Inhibitory Effect(s) of Polymeric Black Tea Polyphenol Fractions on the Formation of [ $\left.{ }^{3} \mathrm{H}\right]-\mathrm{B}(\mathrm{a}) \mathrm{P}-$ Derived DNA Adducts. Journal of Agricultural and Food Chemistry, 52, 4261-4269. http://dx.doi.org/10.1021/jf049979o

[24] Nanjo, F., Goto, K., Seto, R., Suzuki, M., Sakai, M. and Hara, Y. (1996) Scavenging Effects of Tea Catechins and Their Derivatives on 1,1-Diphenyl-2-Picrylhydrazyl Radical. Free Radical Biology and Medicine, 21, 895-902. http://dx.doi.org/10.1016/0891-5849(96)00237-7

[25] Bhattacharyya, N., Seth, S., Tudu, B., Tamuly, P., Jana, A., Ghosh, D., Bandyopadhyay, R., Bhuyan, M. and Sabhapandit, S. (2007) Detection of Optimum Aeration Time for Black Tea Manufacturing Using Electronic Nose. Sensors and Actuators B: Chemical, 122, 627-634. http://dx.doi.org/10.1016/j.snb.2006.07.013

[26] Obanda, M., Owuor, P.O. and Mang'oka, R. (2001) Changes in the Chemical and Sensory Quality Parameters of Black Tea Due to Variations of Aeration Time and Temperature. Food Chemistry, 75, 395-404. http://dx.doi.org/10.1016/S0308-8146(01)00223-0

[27] Owuor, P.O. and Obanda, M. (2007) The Use of Green Tea (Camellia sinensis) Leaf Flavan-3-ol Composition in Predicting Plain Black Tea Quality Potential. Food Chemistry, 100, 873-884. http://dx.doi.org/10.1016/j.foodchem.2005.10.030

[28] Owuor, P.O., Obanda, M., Nyirenda, H.E. and Mandala, W.L. (2008) Influence of Region of Production on Clonal Black Tea Chemical Characteristics. Food Chemistry, 108, 263-271. http://dx.doi.org/10.1016/j.foodchem.2007.09.017

[29] Bailey, R.G., Nursten, H.E. and McDowell, I. (1991) Comparative Study of the Reversed-Phase High-Performance Liquid Chromatography of Black Tea Liquors with Special Reference to the Thearubigins. Journal of Chromatography A, 542, 115-128. http://dx.doi.org/10.1016/S0021-9673(01)88752-5

[30] Leonida, C., Kamunya, S.M., Alakonya, A., Solomon, M.W., Uwimanna, M.A. and Phillip, O.O. (2013) Characterization of 20 Clones of Tea (Camellia sinensis (L.) O. Kuntze) Using ISSR and SSR Markers. Agricultural Science Research Journal, 3, 292-302.

[31] Wachira, F.N., Kamunya, S., Karori, S., Chalo, R. and Maritim, T. (2013) Chapter 1-The Tea Plants: Botanical Aspects. In: Preedy, V.R., Ed., Tea in Health and Disease Prevention, Academic Press, Elsevier Science and Technology, Missouri, 3-17.

[32] Koech, K.R., Wachira, F.N., Ngure, R.M., Wanyoko, J.K., Bii, C.C., Karori, S.M. and Kerio, L.C. (2013) Antimicrobial, Synergistic and Antioxidant Activities of Tea Polyphenols. In: Méndez-Vilas, A., Ed., Microbial Pathogens and Strategies for Combating Them: Science, Technology and Education, Formatex Research Center, Badajoz, 971-981.

[33] Ngure, F.M., Wanyoko, J.K., Mahungu, S.M. and Shitandi, A.A. (2009) Catechins Depletion Patterns in Relation to Theaflavin and Thearubigins Formation. Food Chemistry, 115, 8-14. http://dx.doi.org/10.1016/j.foodchem.2008.10.006

[34] Baruah, A.M. and Mahanta, P.K. (2003) Aeration Characteristics of Some Assamica Clones and Process Optimization of Black Tea Manufacturing. Journal of Agricultural and Food Chemistry, 51, 6578-6588. http://dx.doi.org/10.1021/jf030019w

[35] Bhattacharya, N., Tudu, B., Jana, A., Ghosh, D., Bandhopadhyaya, R. and Bhuyan, M. (2008) Preemptive Identification of Optimum Aeration Time for Black Tea Using Electronic Nose. Sensors \& Actuators, B: Chemical, 131, 110116. http://dx.doi.org/10.1016/j.snb.2007.12.032

[36] Muthumani, T. and Kumar, R.S.S. (2006) Influence of Aeration Time on the Development of Compounds Responsible for Quality in Black Tea. Food Chemistry, 101, 98-102. http://dx.doi.org/10.1016/j.foodchem.2006.01.008

[37] Tu, Y.-Y., Xu, X.-Q., Xia, H.-L. and Watanabe, N. (2005) Optimization of Theaflavin Biosynthesis from Tea Polyphenols Using an Immobilized Enzyme System and Response Surface Methodology. Biotechnology Letters, 27, 269274. http://dx.doi.org/10.1007/s10529-004-8292-4

[38] Myers, R.H., Montgomery, D.C. and Anderson-Cook, C. (2009) Response Surface Methodology: Process and Product Optimization Using Designed Experiments (Wiley Series in Probability and Statistics). Wiley, New York, 704.

[39] Subramanian, N., Venkatesh, P., Ganguli, S. and Sinkar, V.P. (1999) Role of Polyphenol Oxidase and Peroxidase in the Generation of Black Tea Theaflavins. Journal of Agricultural and Food Chemistry, 47, 2571-2578. http://dx.doi.org/10.1021/jf981042y

[40] Kim, Y., Goodner, K.L., Park, J.D., Choi, J. and Talcott, S.T. (2011) Changes in Antioxidant Phytochemicals and Vo- 
latile Composition of Camellia sinensis by Oxidation during Tea Aeration. Food Chemistry, 129, 1331-1342. http://dx.doi.org/10.1016/j.foodchem.2011.05.012

[41] Nadi, M., Mosaffa, N., Karimi, F., Kamalinejad, M., Farrokhi, B., Anissian, A., Pakzad, P., Nadi, M., Mosaffa, N., Karimi, F., Kamalinejad, M., Farrokhi, B., Anissian, A. and Pakzad, P. (2010) Iranian Black Tea and Cowslip Extracts Induce Tumor Necrosis Factor-Alpha Secretion from Mouse Macrophage Cell Culture. Iranian Journal of Pharmaceutical Research, 9, 83-87.

[42] Ghorbanzadeh, B., Shahriari, A. and Tabatabaie, R. (2012) Effect of Optional Consumption of Iranian Black and Green Tea on Lipid Profile of Serum and Liver in High-Fat Diet Rats. Iranian Journal of Diabetes and Obesity, 4, 79-86. 